\title{
CORRECTION
}

\section{Correction to: New clotting disorders that cast new light on blood coagulation and may play a role in clinical practice}

\author{
A. Girolami ${ }^{1}$ - E. Cosi ${ }^{1}$ - S. Ferrari ${ }^{1}$ - A. M. Lombardi ${ }^{1} \cdot$ B Girolami $^{2}$
}

Published online: 20 November 2018

(c) Springer Science+Business Media, LLC, part of Springer Nature 2018

\section{Correction to: \\ Journal of Thrombosis and Thrombolysis (2017) 44:71-75 https://doi.org// \\ https://doi.org/10.1007/s11239-017-1488-y}

The original version of the article unfortunately contained few errors.

The authors wish to correct the following:

The mutation Prothrombin Amrita should be Arg596G; FIX Padua should be Arg338Leu; and Prothrombin polymorphism should be Exon 14 and G20210A.

The original article can be found online at https://doi.org/10.1007/ s11239-017-1488-y.

A. Girolami antonio.girolami@unipd.it

1 Department of Medicine, University of Padua Medical School, Via Ospedale, 105, Padua 35128, Italy

2 Division of Medicine, Padua City Hospital, Padua via G.Falloppio 2, Padua 35128, Italy 